\title{
Molecular characterization of a canine coronavirus NA/09 strain detected in a dog's organs
}

\author{
Vasileios Ntafis • Eftychia Xylouri • Viviana Mari • Maria Papanastassopoulou • \\ Nikolaos Papaioannou • Angelos Thomas · Canio Buonavoglia • Nicola Decaro
}

Received: 8 August 2011/Accepted: 3 October 2011 / Published online: 16 October 2011

(C) Springer-Verlag 2011

\begin{abstract}
In the present study, the detection of a pantropic canine coronavirus $(\mathrm{CCoV})$ strain in a dog with lethal diarrhoea is reported. RT-PCR and real-time RTPCR assays were used for the detection, characterization and quantitation of $\mathrm{CCoV}$. Sequence and phylogenetic analysis of the CCoV NA/09 revealed a high degree of sequence identity with the pantropic strain $\mathrm{CB} / 05$, indicating the presence of $\mathrm{CB} / 05$-like pantropic strains in Greece. The absence of the 38-nucleotide deletion in
\end{abstract}

Nucleotide sequence data reported is available in the GenBank database under the accession number JF682842.

\section{Ntafis $(\bowtie) \cdot$ E. Xylouri}

Department of Anatomy and Physiology of Farm Animals, Faculty of Animal Science and Aquaculture, Agricultural University of Athens, Iera Odos 75, 11855 Athens, Greece e-mail: vasilisntafis@hotmail.com

V. Mari $\cdot$ C. Buonavoglia $\cdot$ N. Decaro

Department of Veterinary Public Health, Faculty of Veterinary Medicine, University of Bari, S.p. per Casamassima km 3, 70010 Valenzano, Bari, Italy

M. Papanastassopoulou

Laboratory of Microbiology and Infectious Diseases, Faculty of Veterinary Medicine, Aristotle University of Thessaloniki, 541 24, Thessaloniki, Greece

\section{N. Papaioannou}

Department of Pathology, Faculty of Veterinary Medicine, Aristotle University of Thessaloniki, 54124 Thessaloniki, Greece

\section{A. Thomas}

Companion Animal Clinic, Faculty of Veterinary Medicine, Aristotle University of Thessaloniki, 54124 Thessaloniki, Greece
ORF3b, which is characteristic of $\mathrm{CB} / 05$, indicates the need to identify new genetic markers for pantropic variants of $\mathrm{CCoV}$, probably in the spike-protein gene region.

Keywords $\mathrm{CCoV} \cdot$ Pantropic $\cdot$ Dog $\cdot$ Genetic markers

Canine coronavirus $(\mathrm{CCoV})$ is a member of the virus family Coronaviridae, order Nidovirales. It is a large, enveloped, single-stranded, positive-sense RNA virus. The genome consists of two overlapping open reading frames (ORF1a and 1b) translated into a polyprotein (precursor of the RNA-dependent RNA polymerase) and several ORFs encoding structural (spike, membrane, envelope and nucleocapsid protein) and non-structural proteins (3a, $3 \mathrm{~b}$, $3 \mathrm{c}, 7 \mathrm{a}$ and $7 \mathrm{~b})[14,18]$. To date, two different genotypes of $\mathrm{CCoV}$ have been recognized, $\mathrm{CCoV}$ type $\mathrm{I}(\mathrm{CCoV}-\mathrm{I})$ and $\mathrm{CCoV}$ type II (CCoV-II) [10]. Furthermore, recently, CCoV-II was divided in two subtypes, CCoV-IIa and $\mathrm{CCoV}-\mathrm{IIb}$, with the second of these arising as a result of a putative recombination event between $\mathrm{CCoV}$-II and transmissible gastroenteritis virus (TGEV) [12, 13]. Recently, $\mathrm{CCoV}$, TGEV and feline coronavirus (FCoV) were included in the same species, Alphacoronavirus 1, of the new genus Alphacoronavirus [2].

$\mathrm{CCoV}$ is the causative agent of enteritis in dogs, with infection being restricted to the intestinal tract. Although $\mathrm{CCoV}$ is characterized by low mortality, and systemic infections are not usual [10], in 2005, a highly pathogenic $\mathrm{CCoV}$ strain $(\mathrm{CB} / 05)$ was detected in an outbreak of a fatal systemic disease in puppies. The virus was isolated from faeces, as well as various parenchymatous organ samples from the dogs [1]. In addition, the disease was reproduced after experimental infection of dogs, with young puppies being more severely affected [11]. 
Sequencing and phylogenetic analysis have demonstrated that $\mathrm{CB} / 05$ belongs to the $\mathrm{CCoV}$-IIa subtype, which includes all "classical" canine coronavirus strains, with a deletion in ORF3b being proposed as a possible genetic marker for the pantropic nature of the strain [10]. Recently, recombinant $\mathrm{CCoV}$-IIb strains were also detected in organs of dogs, though after experimental infection, no systemic signs or virus dissemination through the blood were observed, implying differences in pathobiology among CCoV-IIa pantropic variants and CCoV-IIb strains [12, 23].

In Greece, the presence of $\mathrm{CCoV}$ was recently reported for the first time, in a severe outbreak of enteritis in a kennel. By sequence and phylogenetic analysis, high similarity to the pantropic $\mathrm{CB} / 05$ strain in the most variable region of the $\mathrm{S}$ gene was demonstrated [22]. In the present study, the molecular characterization and sequence analysis findings of a CCoV-IIa pantropic strain, as well as the need for new genetic markers, are reported.

In April 2009, a dead 10-week-old Maltese (13/09) male dog was submitted for laboratory investigation, coming from a pet shop in Thessaloniki, a city in northern Greece. The dog presented inappetence, depression, severe haemorrhagic diarrhoea, vomiting and hypothermia following fever, leading to death one day after the onset of the symptoms. The puppy had been vaccinated with a single dose of a vaccine against canine parvovirus and canine distemper virus three weeks before the onset of the symptoms.

During necropsy examination, linear haemorrhages of the intestinal wall, haemorrhagic enteritis and an ulcerated duodenum were observed. Multiple areas of emphysema and congestion were found at the lungs. The liver was enlarged, friable and yellow-brown in color with multifocal discolored spots. Congested vessels in the dura mater of the brain were also observed.

Faecal and parenchymatous organ samples were tested, using molecular diagnostic assays described previously, for common canine viral pathogens e.g., $\mathrm{CCoV}$ [3], canine parvovirus type 2 (CPV-2) [4, 6, 7], canine distemper virus (CDV) [15] and canine adenovirus type 1 and type 2 (CAV-1 and CAV-2) [17]. For CCoV typing, quantitation and subtyping in faecal and organ samples, two real-time RT-PCR assays [5] and two RT-PCR assays [13] were carried out.

The lung of the dead pup was homogenised $(10 \% \mathrm{w} / \mathrm{v})$ in D-MEM together with antibiotics (penicillin 1,000 $\mathrm{IU} / \mathrm{ml}$, streptomycin $100 \mu \mathrm{g} / \mathrm{ml}$ ), and inoculated into canine fibroma (A-72) cells. Infected cells were monitored daily for the occurrence of cytopathic effect (CPE) and, after five days of incubation, they were tested for $\mathrm{CCoV}$ antigen by an immunofluorescence (IF) assay using a cat polyclonal serum specific for members of the species Alphacoronavirus 1 and a goat anti-cat $\mathrm{IgG}$ conjugated with fluorescein isothiocyanate (Sigma Aldrich, USA).
The $3^{\prime}$ end of the genome of the CCoV-IIa NA/09 strain was amplified as described previously, using viral RNA extracted from the spleen, SuperScript One-Step RT-PCR for Long Templates (Invitrogen s.r.l., Italy) and six RTPCR assays, specific for overlapping fragments, encompassing ORFs 2, 3a, 3b, 3c, 4, 5, 6, 7a and 7b [9]. The nucleotide sequence was determined in both directions for each fragment. PCR amplicons were sequenced by a commercial facility (Beckman Coulter Genomics, United Kingdom). Sequence assembly and analysis were carried out using the BioEdit software package [16] and the National Center for Biotechnology Information (NCBI; http://www.ncbi.nlm.nih.gov) analysis tool. The NetNGlyk 1.0 Server was used for the prediction of N-linked glycosylation sites, signal peptides and transmembrane helices (http://www.cbs.dtu.dk/services/, NetGlyc, SignalP and TMHMM, respectively). Phylogenetic analysis was conducted using the MEGA4 program, and a tree based on the $\mathrm{S}$ protein was constructed using the neighbor-joining method [24].

CCoV RNA was detected in the faeces, lungs, spleen, kidneys, pancreas, heart, liver and brain of the dead puppy. Using genotype-specific real-time RT-PCR assays, both genotypes, CCoV-I and CCoV-II $\left(5.3 \times 10^{3}\right.$ and $6.13 \times 10^{5}$ RNA copies/ $\mu 1$ of template, respectively), were detected in the faeces, while only CCoV-II was detected in all organ samples. In detail, CCoV-II was detected in liver $\left(5.11 \times 10^{3}\right.$ RNA copies/ $\mu$ l of template), spleen $\left(1.06 \times 10^{5} \mathrm{RNA}\right.$ copies $/ \mu$ l of template $)$, pancreas $(7.03 \times$ $10^{1}$ RNA copies/ $\mu$ l of template), kidney $\left(1.21 \times 10^{3}\right.$ RNA copies/ $\mu$ l of template), lungs $\left(7.68 \times 10^{4}\right.$ RNA copies $/ \mu 1$ of template), heart $\left(8.2 \times 10^{4}\right.$ RNA copies/ $\mu$ l of template $)$ and brain $\left(2.03 \times 10^{2}\right.$ RNA copies/ $\mu$ l of template $)$. Regarding subtype characterization, the CCoV-II strain detected in faecal and in all organ samples was characterized as CCoV-IIa.

Despite several attempts, the virus was not adapted to growth in vitro, as demonstrated by the absence of cytopathic effect in inoculated cells and by negative results in the IF assay, even after three passages on cell cultures.

Regarding other canine viral pathogens, the dog tested positive for a CPV-2a field strain.

A total of 8,809 nucleotides were determined for strain NA/09, encompassing ORFs 2 (S protein), 3a, 3b, 3c, 4 (E protein), 5 (M protein), 6 ( $\mathrm{N}$ protein), $7 \mathrm{a}$ and $7 \mathrm{~b}$. Alignment of an 8,767-nucleotide part of the sequence with TGEV, $\mathrm{CCoV}$ and $\mathrm{FCoV}$ reference strains available in GenBank showed the highest identity to CCoV-IIa pantropic reference strain $\mathrm{CB} / 05$ (DQ112226) (97.7\%). The minimum conserved signal for transcription (CTAAAC) was present upstream of all of the ORFs (ORF 2, 3, 4, 5, 6 and 7).

The spike protein gene was 4,365 nucleotides long, encoding a protein of 1,454 amino acids. When compared to 
strain $\mathrm{CB} / 05$, no insertions or deletions were observed. The spike protein of NA/09, when compared with the analogous proteins of $\mathrm{CCOV}$, TGEV and $\mathrm{FCoV}$ reference strains, showed the highest similarity to $\mathrm{CB} / 05 \quad(98.2 \%$ aa) (Table 1). Analysis using the NetNGlyk 1.0 Server showed that the protein contained a putative signal peptide (cleavage sites at positions Ser 19 to Thr 20, as in strain CB/05) and a transmembrane domain (positions 1,394 - 1,416 of the $\mathrm{S}$ gene). The $\mathrm{S}$ protein contained 31 potential N-linked glycosylation sites. Phylogenetic analysis revealed that the Greek strain was more closely related to the CB/05 pantropic reference strain detected in dogs' organs (Fig. 1).

The genomic region located between the $\mathrm{S}$ and $\mathrm{E}$ genes of both strains was found to encode three presumptive nonstructural proteins. Nsp3a, 3b and 3c proteins were 78, 71 and 244 amino acids long, respectively. Regarding ORF3b, the 38-nucleotide deletion of the $\mathrm{CB} / 05$ was not observed (Fig. 2).

The envelope protein was found to be 82 amino acids in length, like in most canine coronavirus strains. A transmembrane domain was predicted between residue 15 and 37. The Greek strain had $100 \%$ amino acid identity to $\mathrm{CB} /$ 05 and to two CCoV-IIb strains detected in dogs' organs (119/08 and 341/05). The membrane protein (M protein) was found to be 262 amino acids long. It contained three potential N-linked glycosylation sites, a putative signal peptide (cleavage sites at positions Gly 16 to Glu 17) and three transmembrane domains (positions 47-69, 76-98 and 113-135). The $M$ protein had the highest amino acid

Table $1 \mathrm{NA} / 09 \mathrm{~S}$ protein similarities, compared to $\mathrm{S}$ proteins of $\mathrm{CCoV}$, TGEV and FCoV reference strains

\begin{tabular}{ll}
\hline Virus strain & $\begin{array}{l}\text { \% Similarity to the } \\
\text { NA/09 S protein }\end{array}$ \\
\hline CCoV-IIa/CB/05/DQ112226 & 98.2 \\
CCoV-IIa/1-71/AY796289 & 94 \\
CCoV-IIa/K378/X77047 & 93.3 \\
CCoV-IIa/INSAVC/D13096 & 92.5 \\
CCoV-IIa/BGF10/AY342160 & 92 \\
CCoV-I/23/03/AY307021 & 43.6 \\
CCoV-I/Elmo/02/AY307020 & 42.9 \\
CCoV-IIb/341/05/EU856361 & 83.3 \\
CCoV-IIb/119/08/EU924791 & 83.7 \\
CCoV-IIb/430/07/EU924790 & 83.2 \\
CCoV-IIb/174/06/EU856362 & 82 \\
FCoV-I/UCD1/AB088222 & 43.2 \\
FCoV-I/Black/EU186072 & 42.6 \\
FCoV-II/79-1683/X80799 & 96 \\
FCoV-II/79-1146/NC007025 & 94.4 \\
TGEV/TS/DQ201447 & 80.3 \\
TGEV/Purdue/NC002306 & 80.3 \\
\hline
\end{tabular}

sequence identity to those of the $\mathrm{CCoV}-\mathrm{IIb}$ reference strains (119/08 and 430/07) and to that of CB/05 (99.6\% and $99.2 \%$, respectively). The $\mathrm{N}$ protein (nucleoprotein) was found to be 382 amino acids in length. The Greek strain shared the highest amino acid identity with CCoVIIb 119/08 and CB/05 (99.7\% and 99.4\%, respectively). ORF7 of both strains was found to encode two presumptive non-structural proteins. Nsp7a and 7b were 101 and 213 amino acids in length, and they were conserved with respect to the CCoV-II reference strains.

Coronaviruses are characterized by high genetic diversity. The high frequency of mutations, due to the high rate of mistakes of the RNA-dependent RNA polymerase, as well as frequent recombination are considered the main mechanisms of coronaviruses evolution, leading to the emergence of new strains, subtypes and genotypes within species and changes regarding tissue or even host tropism [26]. In the present study, a CCoV strain, spreading to the internal organs, was detected and analysed by molecular techniques. By means of sequence and phylogenetic analysis, a high similarity to the pantropic $\mathrm{CB} / 05$ variant was shown. This study, the second one reporting the genetic characterization of a $\mathrm{CCoV}$ pantropic strain, suggests that pantropic $\mathrm{CCoV}$ variants are present in Greece and can be associated with fatal disease in puppies [9]. However, the observed mortality could be due to the dual CPV/pantropic $\mathrm{CCoV}$ infection, considering that mixed infections usually display a more severe course and higher mortality [8]. In addition, recent studies have demonstrated that the outcome of $\mathrm{CB} / 05$ infection is not invariably lethal, but, at least under experimental conditions, its main consequence is represented by a profound, long-lasting lymphopenia involving both B and T cells [20].

By means of real-time RT-PCR, the tissue distribution of NA/09 was determined. Viral RNA was detected in several parenchymatous organs and in high concentration, suggesting the pantropic nature of the variant. Detection and quantitation of the viral RNA in the heart and the pancreas is reported for the first time. The detection of CCoV-I, which was restricted to the faecal samples, suggests that the pantropic NA/09 strain has the advantage of disseminating in the organism, revealing differences in the pathobiology of the pantropic variants with respect to common $\mathrm{CCoV}$ enteric strains.

Regarding $\mathrm{CCoV}$, mutations are considered to play a key role in the emergence of the pantropic variant $\mathrm{CB} / 05$ [9]. The truncated form of ORF3b, observed in CB/05, was not present in NA/09. That mutation was considered to be a possible genetic marker for pantropic variants [9]. However, similar deletions in ORF3b have been observed in common enteric strains, as in 1-71 (Fig. 2) [19], and truncated nsp3b has been associated with attenuated coronavirus strains [25]. On the other hand, a high similarity in 
Fig. 1 Neighbor-joining tree of the Greek strain, based on the $\mathrm{S}$ protein. The tree is rooted on the group 2 canine respiratory coronavirus $(\mathrm{CRCoV})$. The numbers represent the percentage of replicate trees based on 1,000 bootstrap replicates. The scale bar represents the number of amino acid substitutions

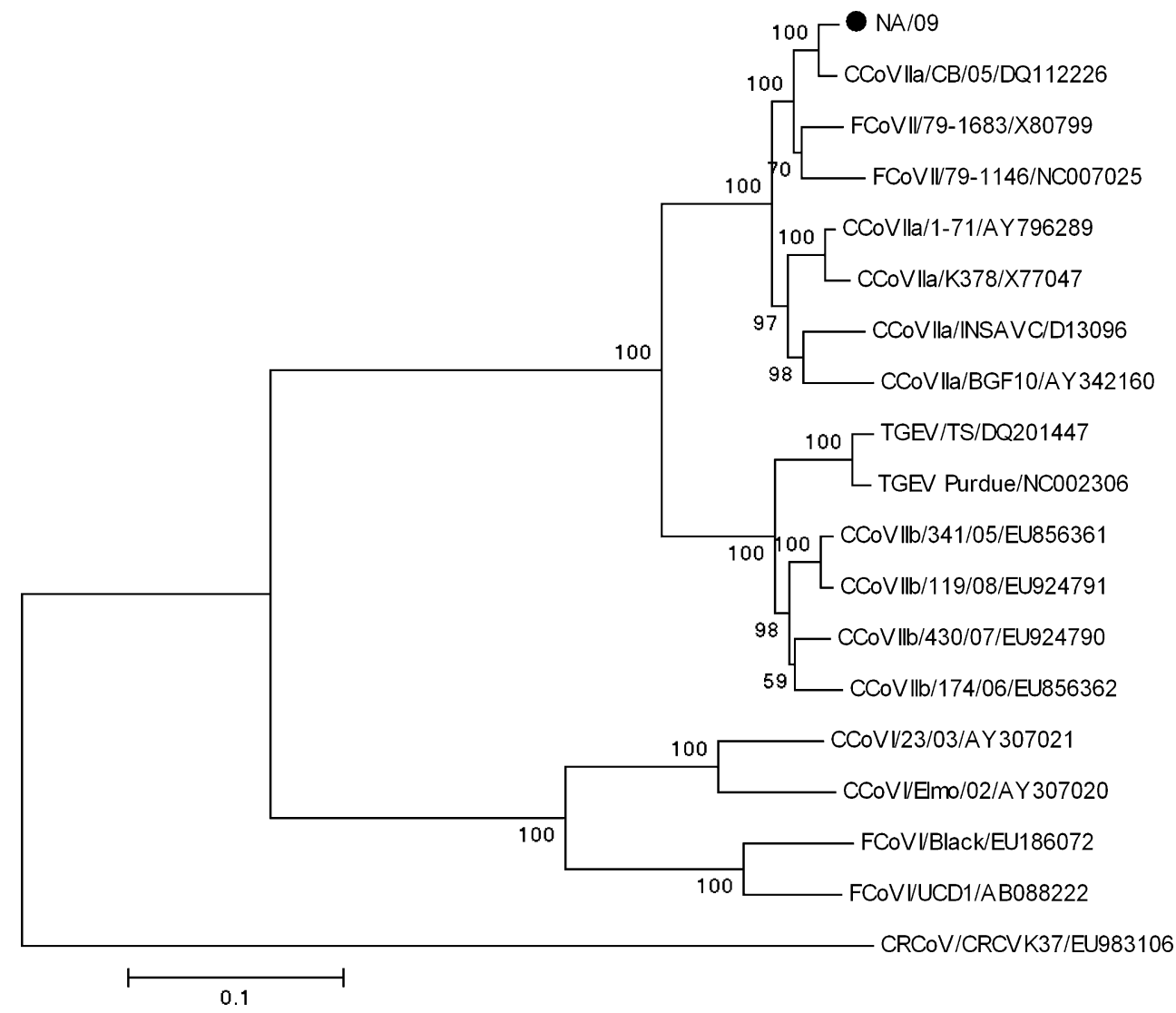

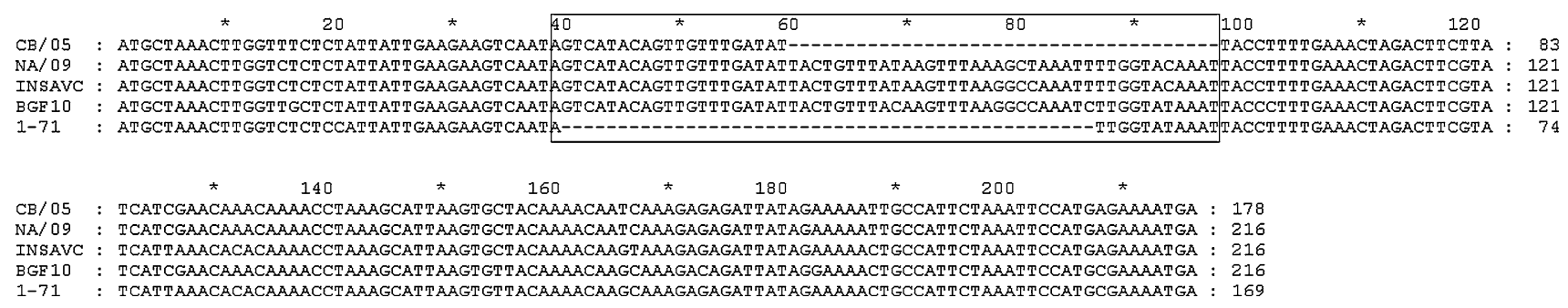

Fig. 2 ORF3b nucleotide sequence of the NA/09 strain, aligned with CCoV-IIa reference strains CB/05, INSAVC, BGF10 and 1-71. The nucleotide deletions of $\mathrm{CB} / 05$ and 1-71 are enclosed in a rectangle

the $\mathrm{S}$ protein was observed between $\mathrm{NA} / 09$ and $\mathrm{CB} / 05$ strains. Since the $\mathrm{S}$ protein is responsible for receptor attachment and changes in tissue tropism have been associated with mutations in the $\mathrm{S}$ gene $[18,21]$, it is likely that specific genetic markers for pantropic strains will be identified in this region.

In conclusion, in the present study, the detection, quantitation and molecular analysis of a pantropic $\mathrm{CCoV}$ variant is reported. In addition, it is suggested that pantropic variants can be identified in the heart and the pancreas. The emergence of strains that are able to disseminate and cause systemic infection suggests that canine coronaviral infections may be more interesting and severe than thought in the past. Further studies are necessary in order to determine the circulation of pantropic CCoV strains among the dog population and to identify specific genetic markers that can be useful for understanding virus pathobiology and epidemiology.

Acknowledgments Ntafis Vasileios is grateful to Alexander S. Onassis Public Benefit Foundation for doctoral funding.

Conflict of interest The authors declare that they have no conflict of interest.

\section{References}

1. Buonavoglia C, Decaro N, Martella V, Elia G, Campolo M, Desario C, Castagnaro M, Tempesta M (2006) Canine coronavirus highly pathogenic for dogs. Emerg Infect Dis 12:492-494

2. Carstens EB (2010) Ratification vote on taxonomic proposals to the International Committee on Taxonomy of Viruses. Arch Virol 155:133-146 
3. Decaro N, Pratelli A, Campolo M, Elia G, Martella V, Tempesta M, Buonavoglia C (2004) Quantitation of canine coronavirus RNA in the faeces of dogs by TaqMan RT-PCR. J Virol Methods 119:145-150

4. Decaro N, Elia G, Martella V, Desario C, Campolo M, Di Trani L, Tarsitano E, Tempesta M, Buonavoglia C (2005) A real-time PCR assay for rapid detection and quantitation of canine parvovirus type 2 in the feces of dogs. Vet Microbiol 105:19-28

5. Decaro N, Martella V, Ricci D, Elia G, Desario C, Campolo M, Cavaliere N, Trani LD, Tempesta M, Buonavoglia C (2005) Genotype-specific fluorogenic RT-PCR assays for the detection and the quantitation of canine coronavirus type I and type II RNA in faecal samples of dogs. J Virol Methods 130:72-78

6. Decaro N, Elia G, Desario C, Roperto S, Martella V, Campolo M, Lorusso A, Cavalli A, Buonavoglia C (2006) A minor groove binder probe real-time PCR assay for discrimination between type 2-based vaccines and field strains of canine parvovirus. J Virol Methods 136:65-70

7. Decaro N, Elia G, Martella V, Campolo M, Desario C, Camero M, Cirone F, Lorusso E, Lucente MS, Narcisi D, Scalia P, Buonavoglia $C$ (2006) Characterization of the canine parvovirus type 2 variants using minor groove binder probe technology. J Virol Methods 133:92-99

8. Decaro N, Martella V, Desario C, Bellacicco AL, Camero M, Manna L, D'aloja D, Buonavoglia C (2006) First detection of canine parvovirus type $2 \mathrm{c}$ in pups with haemorrhagic enteritis in Spain. J Vet Med B Infect Dis Vet Public Health 53:468-472

9. Decaro N, Martella V, Elia G, Campolo M, Desario C, Cirone F, Tempesta M, Buonavoglia C (2007) Molecular characterization of the virulent canine coronavirus $\mathrm{CB} / 05$ strain. Virus Res 125:54-60

10. Decaro N, Buonavoglia C (2008) An update on canine coronaviruses: viral evolution and pathobiology. Vet Microbiol 132:221-234

11. Decaro N, Campolo M, Lorusso A, Desario C, Mari V, Colaianni ML, Elia G, Martella V, Buonavoglia C (2008) Experimental infection of dogs with a novel strain of canine coronavirus causing systemic disease and lymphopenia. Vet Microbiol $128: 253-260$

12. Decaro N, Mari V, Campolo M, Lorusso A, Camero M, Elia G, Martella V, Cordioli P, Enjuanes L, Buonavoglia C (2009) Recombinant canine coronavirus related to transmissible gastroenteritis virus of swine are circulating in dogs. J Virol 83(3):1532-1537

13. Decaro N, Mari V, Elia G, Addie DD, Camero M, Lucente MS, Martella V, Buonavoglia C (2010) Recombinant canine coronaviruses in dogs, Europe. Emerg Infect Dis 16:41-47
14. Enjuanes L, Brian D, Cavanagh D, Holmes K, Lai MMC, Laude H, Masters P, Rottier PJM, Siddell SG, Spaan WJM, Taguchi F, Talbot P (2000) Coronaviridae. In: van Regenmortel MHV et al (eds) Virus taxonomy. Classification and nomenclature of viruses. Academic Press, New York, pp 835-849

15. Frisk AL, Konig M, Moritz A, Baumgartner W (1999) Detection of canine distemper virus nucleoprotein RNA by reverse transcription-PCR using serum, whole blood, and cerebrospinal fluid from dogs with distemper. J Clin Microbiol 37:3634-3643

16. Hall TA (1999) BioEdit: a user-friendly biological sequence alignment editor and analysis program for Windows 95/98/NT. Nucl Acids Symp 41:95-98

17. Hu RL, Huang G, Qiu W, Zhong ZH, Xia XZ, Yin Z (2001) Detection and differentiation of CAV-1 and CAV-2 by polymerase chain reaction. Vet Res Commun 25:77-84

18. Lai MMC, Holmes KV (2001) Coronaviridae: the viruses and their replication. In: Knipe DM et al (eds) Fields virology, 4th edn. Lippincott Williams and Wilkins, Philadelphia, pp 1163-1185

19. Ma G, Wang Y, Lu C (2008) Molecular characterization of the $9.36 \mathrm{~kb} \mathrm{C}$-terminal region of canine coronavirus 1-71 strain. Virus genes 36:491-497

20. Marinaro M, Mari V, Bellacicco AL, Tarsitano E, Elia G, Losurdo M, Rezza G, Buonavoglia C, Decaro N (2010) Long-lasting depletion of circulating CD4+ $\mathrm{T}$ lymphocytes and acute monocytosis after pantropic canine coronavirus infection in dogs. Virus Res 152:73-78

21. Masters PS (2006) The molecular biology of coronaviruses. Adv Virus Res 66:193-292

22. Ntafis V, Mari V, Danika S, Fragkiadaki E, Buonavoglia C (2010) An outbreak of canine coronavirus in a Greek kennel. J Vet Diagn Invest 22:320-323

23. Ntafis V, Mari V, Decaro N, Papanastassopoulou M, Papaioannou N, Mpatziou R, Buonavoglia C, Xylouri E (2011) Isolation, tissue distribution and molecular characterization of two recombinant canine coronavirus strains. Vet Microbiol 151:238-244

24. Tamura K, Dudley J, Nei M, Kumar S (2007) MEGA4: Molecular Evolutionary Genetics Analysis (MEGA) Software version 4.0. Mol Biol Evol 24:1596-1599

25. Wesley RD, Woods RD, Cheung AK (1990) Genetic basis for the pathogenicity of transmissible gastroenteritis virus. J Virol 64:4761-4766

26. Woo PCY, Lau SKP, Huang Y, Yuen KY (2009) Coronavirus diversity, phylogeny and interspecies jumping. Exp Biol Med 234:1117-1127 